\title{
Closed Carbon Chains in Organic Chemistry.
}

DROF. W. H. PERKIN chose " The Early History of the Synthesis of Closed Carbon Chains" as the subject of the first Pedler lecture, which he delivered before the Chemical Society on May 30. It was, he said, very difficult to appreciate the fact that not more than fifty years ago the idea was firmly fixed in the minds of chemists that organic compounds must be sharply divided into the group having open carbon chains and the group having six-membered rings. The lecturer gave an interesting account of his discussions, as a young student, with Victor Meyer and Baeyer regarding the possibility of preparing compounds containing rings composed of three, four, or five carbon atoms, and of his resolve to prosecute researches in that direction.

The first step consisted in the condensation of trimethylene bromide with the sodium derivative of acetoacetic ester, followed by hydrolysis, whereby a product then believed to be acetyltetramethylenecarboxylic acid, but afterwards shown to be methyldehydrohexonecarboxylic acid, was obtained. Before the erroneous interpretation had been corrected, however, the new method was vigorously developed in various directions, a substance which, indeed, proved to be tetramethylenecarboxylic acid being obtained in 1883 by the action of trimethylene bromide on the sodium derivative of malonic acid, followed by hydrolysis and elimination of carbon dioxide.

Two years previously, Markownikoff and Krestownikoff had obtained an acid which the lecturer and E. Haworth afterwards proved to be trans-tetramethylene-1:3-dicarboxylic acid; it was remarkable that this earlier observation attracted little attention at the time, and remained undeveloped. Experiments on the action of ethylene bromide in place of tri- methylene bromide on the sodium derivatives of acetoacetic ester and malonic ester brought the lecturer into conflict with Fittig, who with his pupils was at that time investigating the conditions of formation and the properties of lactones. Prof. Perkin gave a brief account of the evidence which led to the recognition of the formation of acids derived from trimethylene.

The next step was to devise a method for the preparation of a derivative of the five-carbon ring. Tetramethylene bromide was then unknown, but ten years later it was obtained accidentally during the preparation of pentamethylene bromide; on condensation with the sodium derivative of malonic ester it readily yielded pentamethylenedicarboxylic ester, this on hydrolysis and elimination of carbon dioxide affording the long-sought pentamethylenecarboxylic acid. Similarly, hexamethylenecarboxylic acid was synthesised from pentamethylene bromide, and was shown to be identical with hexahydrobenzoic acid resulting from the reduction of benzoic acid. In the meantime, an alternative method for the synthesis of the five-carbon ring had been devised in 1885; the disodium derivative of pentanetetracarboxylic ester was treated with bromine, the resulting pentamethylenetetracarboxylic ester then affording pentamethylene-1:2-dicarboxylic acid. The demonstration of the stability of the five-carbon ring confirmed the views which Baeyer had, but a few months previously, developed in his "Spannungstheorie".

Finally, the lecturer referred to the syntheses of hydrindene and tetrahydronaphthalene, published conjointly with Baeyer in 1884. Interaction between o-xylylene bromide (which proved troublesome on account of its severe effect on the eyes) and malonic ester proceeded exactly as Baeyer predicted.

\section{The Fauna of Scotland during the Ice Age.}

$\mathrm{N}$ his recently published presidential address to the Royal Physical Society of Edinburgh (Proc., vol. 21, Part 4, February 1929), Dr. James Ritchie discussed the Ice Age in Scotland in its faunistic bearings. While Scotland must have shared in some degree the fluctuations of climate which have left traces so marked on the neighbouring shores of continental Europe, the earlier fluctuations either left no material remains or these have been removed by subsequent glaciation, for there is no faunistic evidence of the long series of changes which represents the early ice age or altdiluvium of continental geologists. The Scottish Ice Age exhibits but a relatively short section of the Pleistocene glacial epoch.

The remains of early glacial animals in Scotland are extraordinarily scanty, but they belong to the most important of all the animals as indicators of the period of their sojourn-the mammoth, the woolly rhinoceros, and the reindeer. The association of these three animals indicates a period corresponding to the Third Terrace of the Thames Valley. The mammoth and reindeer remains of Kilmaurs were overlaid by an extensive deposit of boulder clay, indicating conditions of ice-covered land in which even such sub-arctic animals could not have survived. Their appearance in Scotland therefore must date to a preceding warmer period which was followed by a major glaciation.

The known distribution of the mammoth in Scotland extends from Berwickshire through Midlothian to Lanarkshire and Ayrshire. Northward migration of the mammoth may have been prevented by a water barrier formed by the junction of the estuaries of the Forth and Clyde. Such a condition in the midland valley would be accounted for by a relatively slight subsidence of the land. Representative animals of the later glacial faunas have been found in Scotland only in isolated spots, with the exception of the fairly extensive faunas first discovered by Drs. Peach and Horne in limestone caves near Inchnadamph, now being further explored by Dr. Ritchie, Mr. J. E. Cree, and Mr. J. G. Callander.

The oldest fauna so far discovered appeared after the cave-riddled hill, more than 1000 feet above sealevel, had been set free from an ice-cap which left enormous deposits of silt in the inner cave, and is an arctic fauna containing scarce remains of reindeer, many arctic rodents, the arctic wolf, lynx, and a very large bear. A considerable period must have elapsed before the second fauna made its appearance, when the animal remains became involved in streams flowing off the valley glacier: this fauna was predominatingly a reindeer fauna, remains of more than 400 individual reindeer having been discovered in a single cave of relatively small size. There is no trace here of modern Scottish animals. These appear in a higher layer which contains for the first time remains of red deer and, on account of the skeletal character and mode of burial of human remains in it, may be regarded as belonging to the period of Azilian culture, between the Palæolithic and Neolithic Ages.

No. 3111, VoL. 123] 